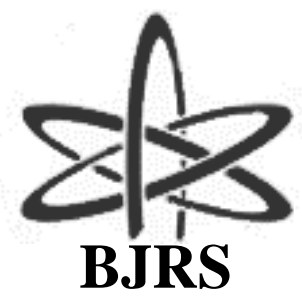

\author{
BRAZILIAN JOURNAL \\ $\mathrm{OF}$ \\ RADIATION SCIENCES \\ 08-01A (2020) 01-10
}

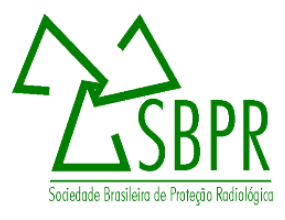

\title{
Evaluation of the performance of radioprotection ionization chambers used in radiometric survey of clinical systems
}

\author{
Silva $^{\mathrm{a}}$, E., Santos ${ }^{\mathrm{b}}$, L.R., Assemany ${ }^{\mathrm{a}}$, L.P.F, Potiens ${ }^{\mathrm{a}}$, M.P.A. \\ ${ }^{a}$ Instituto de Pesquisas Energéticas e Nucleares (IPEN-CNEN), Cep 05508-000, São Paulo, SP, Brazil \\ ${ }^{b}$ Instituto Federal de Educação, Ciência e Tecnologia de São Paulo (IFSP), Cep 01109-010, São Paulo, SP, Brazil \\ ezequiel.fisica@gmail.com
}

\begin{abstract}
The use of ionizing radiation for medical purposes was a major advancement for society due to the various possibilities of use for the treatment and diagnosis of diseases. On the other hand, knowledge about the damage caused by the biological effects of ionizing radiation requires a continuous improvement of the quality control of diagnostic radiology. Radiation detector equipment is used to measure the levels of radiation emitted by sources be they natural or artificial. For practicality and precision, among the most commonly used detectors are the ionization chambers. Especially in outdoor areas climatic factors may affect the behavior of these detectors at the time of measurement, but Brazilian legislation only recommends the calibration of these measuring instruments in a traceable laboratory every two years to ensure their reliability. The objective of this work was to evaluate the performance of an ionization chamber used in radioprotection measurements in diagnostic radiology equipment, considering the climatic variations in the different regions of Brazil. For this, a system was developed to simulate the environmental conditions found for the parameters of temperature and humidity at the time of clinical measurements, making it possible to estimate the influence of these factors on the values obtained.
\end{abstract}

Keywords: ionization chamber; dosimetry; radiodiagnostic 


\section{INTRODUCTION}

The use of ionizing radiation in diagnostic radiology is a powerful tool used in medical and dentistry procedures. Among the artificial sources, most of these contributions come from their use in medicine, especially diagnostic radiology accounting for $90 \%$ in developed countries [1].

Radiological equipment in operation throughout the national territory should be evaluated periodically $[2,3]$ reaffirming the need for reliability of measurements, measurement errors, and performance of the ionization chambers (IC) can affect the entire radioprotection system operational chain of the diagnostic radiology center.

Therefore, quantifying the use of ionizing radiations and operating within acceptable and/or controllable limits, for occupationally exposed individuals, patients undergoing procedures and for the general public is critical.

Performance tests should be applied to IC in order to verify the accuracy of the instrument responses [4] in the measurement and its behavior over time.

Calibration procedures are established in a metrology laboratory with well-defined physical parameters, such as x-ray beam qualities and environmental conditions recommended by international standards, (ISO 4037) Radiological protection X and gamma reference radiation for calibrating dosimeters and dose rate meters and for determining their response as a function of photon [4] the International Atomic Energy Agency (IAEA).However, these controlled conditions are not maintained when using IC in routine measurements, when they are exposed to adverse environmental conditions. The continental dimensions of Brazil provide moisture and temperature factors with great variation from one state to another.

To determine the influence of these external factors on IC used in the field in any part of Brazil, considering the environmental conditions of humidity and temperature is prerequisite to operate within acceptable limits established by the actual standards, guaranteeing the reliability and quality of the measured data. 


\section{MATERIALS AND METHODS}

To make the evaluation of the behavior of a radioprotection IC as proposed in this study, it is necessary to initially calibrate the system in the reference radiation qualities shown at Table 1 . The setup used to calibrate the IC is shown in the Figure 1. Thereafter, the IC should be subjected to stability tests to ensure that its performance is adequate. Therefore, IC can be used in the climate system designed to vary environmental conditions. The flowchart of Figure 2 shows these applied items.

Table 1: Characteristics of the radiation protection qualities (ISO, Series N)

\begin{tabular}{cccc}
\hline Radiation quality & $\begin{array}{c}\text { X ray tube voltage } \\
(\mathbf{k V})\end{array}$ & Total filtration & $\begin{array}{c}\text { Nominal first HVL } \\
(\mathbf{m m ~ C u})\end{array}$ \\
\hline N-60 & 60 & $4 \mathrm{~mm} \mathrm{Al}+0.6 \mathrm{~mm} \mathrm{Cu}$ & 0.25 \\
$\mathrm{~N}-80$ & 80 & $4 \mathrm{~mm} \mathrm{Al}+2 \mathrm{~mm} \mathrm{Cu}$ & 0.612 \\
$\mathrm{~N}-100$ & 100 & $4 \mathrm{~mm} \mathrm{Al}+5 \mathrm{~mm} \mathrm{Cu}$ & 1.14 \\
$\mathrm{~N}-150$ & 150 & $4 \mathrm{~mm} \mathrm{Al}+2.5 \mathrm{~mm} \mathrm{Sn}$ & 2.4 \\
\hline
\end{tabular}

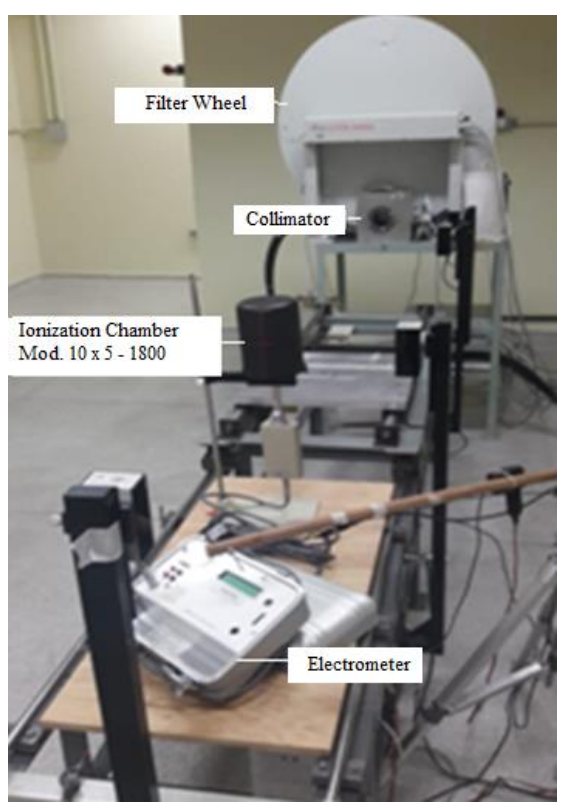

Figure 1: Schematic assembled for calibrate 


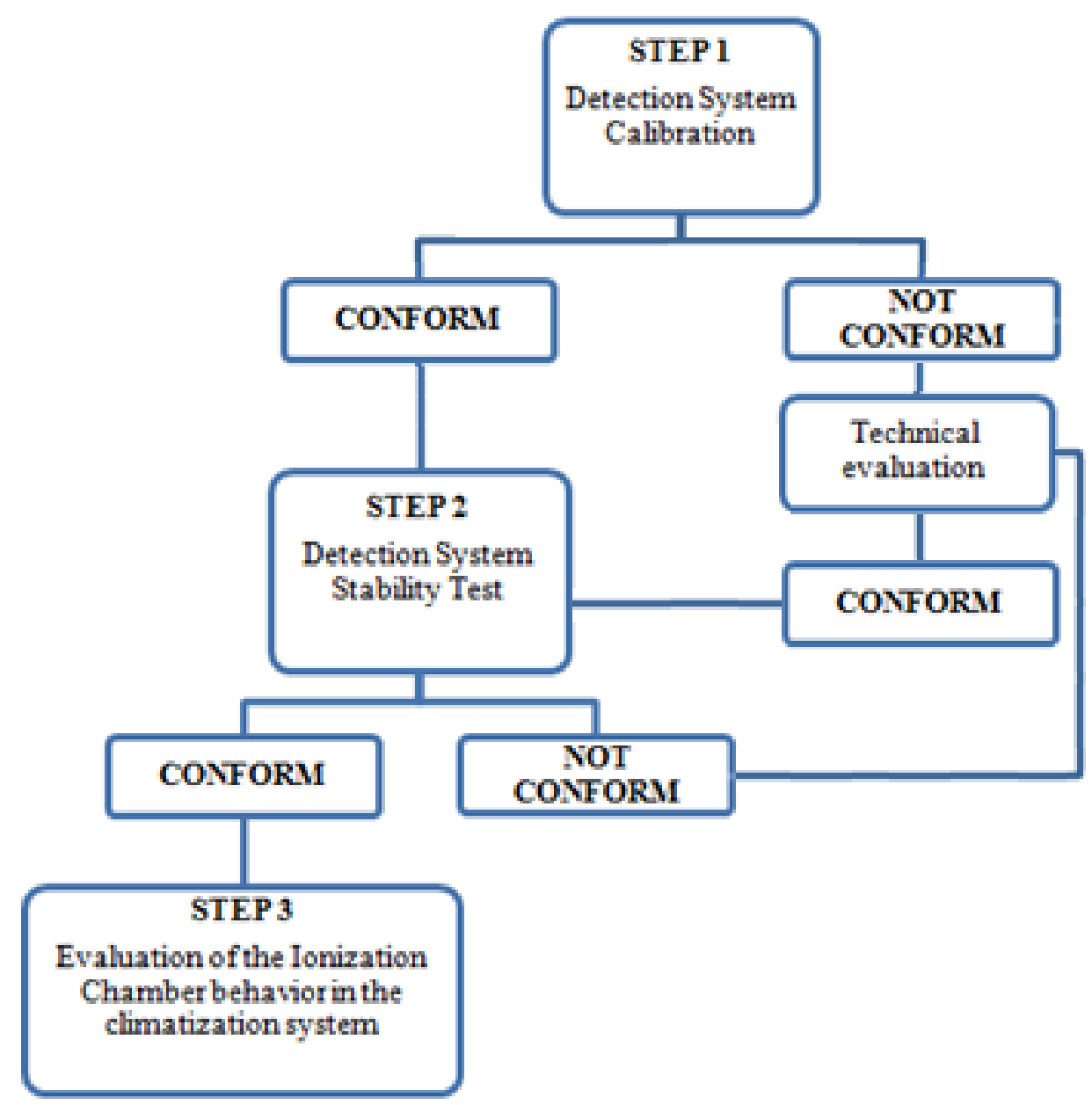

Figure 2: Sequence flowchart performed to assess IC behavior under different environmental conditions

The radiation system used is a Radical ionization chamber, model $10 \times$ 5-1800 couples at a radical electrometer, model 9015.

The radiation Emitting Systems is a Pantak / Seifert X-ray system, Isovolt160 HS model, in the clinical diagnostic radiology operating range $(50 \mathrm{kV}-150 \mathrm{kV})$, located at the Instrument Calibration Laboratory (LCI) of the Institute for Energy and Nuclear Research (IPEN).

To do the stability tests and the measurements inside the climate system it was used the check source of ${ }^{90} \mathrm{Sr}+{ }^{90} \mathrm{Y}$, PTW, mod. $8921 \mathrm{~S} / \mathrm{N} 1294$ with activity of 33MBq (1994)

To perform the tests proposed in this work, it was necessary to build a climate system for temperature and humidity parameters, consisting of a ventilation system, a heating system with 
temperature controller and an acrylic box with adequate dimensions for the test. The accessory instruments used were:

- GTech Air Humidifier - Mod. Alergy Free 35W

- VentiSol Heater - Mod. AQ 01 800W

- Fans - Mod. Mini Fan 4.5W

- Western analog external thermometer - Celsius Fahrenheit graduation

- Ageon Mod. G101 Digital Color Temperature Controller

- Lufft Mod. Opus 20 temperature, humidity and pressure measuring station

- Polymethyl methacrylate (PPMA) enclosure with dimensions of $0.60 \mathrm{mx} 0.65 \mathrm{mx} 0.60 \mathrm{~m}$

Aluminum foil

- Styrofoam plates ( $2 \mathrm{~cm}$ thick)

Initially, with a calibrated dosimetric system, quality control was performed from a series of 10 measurements taken with the control source and another series of 10 measurements without the control source with a time of 1 minute for each measurement, determining the initial condition.

In accordance with current regulations [4], the coefficient of variation between cumulative dose rates with the verification source and without the verification source shall be less than $5 \%$.

For the simulated weather condition, the IC must remain in the acclimatization chamber for 15 minutes to establish thermal equilibrium according to the manufacturer's manual instructions.

For this simulation, temperature and humidity data were selected over a period of one year using the National Institute of Meteorology (INMET) database [6].

In this work, the simulated climatic conditions were from the city of Belém, the selected data were presented in four series with the average temperature and humidity parameters of three hours as shown in Table 2.

For each simulated series, 10 measurements with the control source and 10 measurements without the control source were performed with a time of 1 minute for each measurement, checking the behavior of the IC response. 
Table 2: Brazil - North Region -Amazonas State- Manaus Period of data capture: March 27, 2017 until March 28, 2018

\begin{tabular}{ccc}
\hline $\begin{array}{c}\text { Simulated } \\
\text { Period }\end{array}$ & $\begin{array}{c}\text { Average temperature } \\
\text { in the period }\left({ }^{\circ} \mathrm{C}\right)\end{array}$ & $\begin{array}{c}\text { Average humidity in } \\
\text { the period }(\%)\end{array}$ \\
\hline $7 \mathrm{~h}-9 \mathrm{~h}$ & $25.86 \pm 0.04$ & $85.39 \pm 0.20$ \\
$10 \mathrm{~h}-12 \mathrm{~h}$ & $26.44 \pm 0.05$ & $85.47 \pm 0.21$ \\
$13 \mathrm{~h}-15 \mathrm{~h}$ & $29.76 \pm 0.07$ & $74.02 \pm 0.33$ \\
$16 \mathrm{~h}-18 \mathrm{~h}$ & $31.26 \pm 0.08$ & $67.60 \pm 0.40$ \\
\hline
\end{tabular}

The mounted acclimatization system with the heating, humidity and ventilation control accessories coupled can be seen in Figure 3.

(d)

(a)

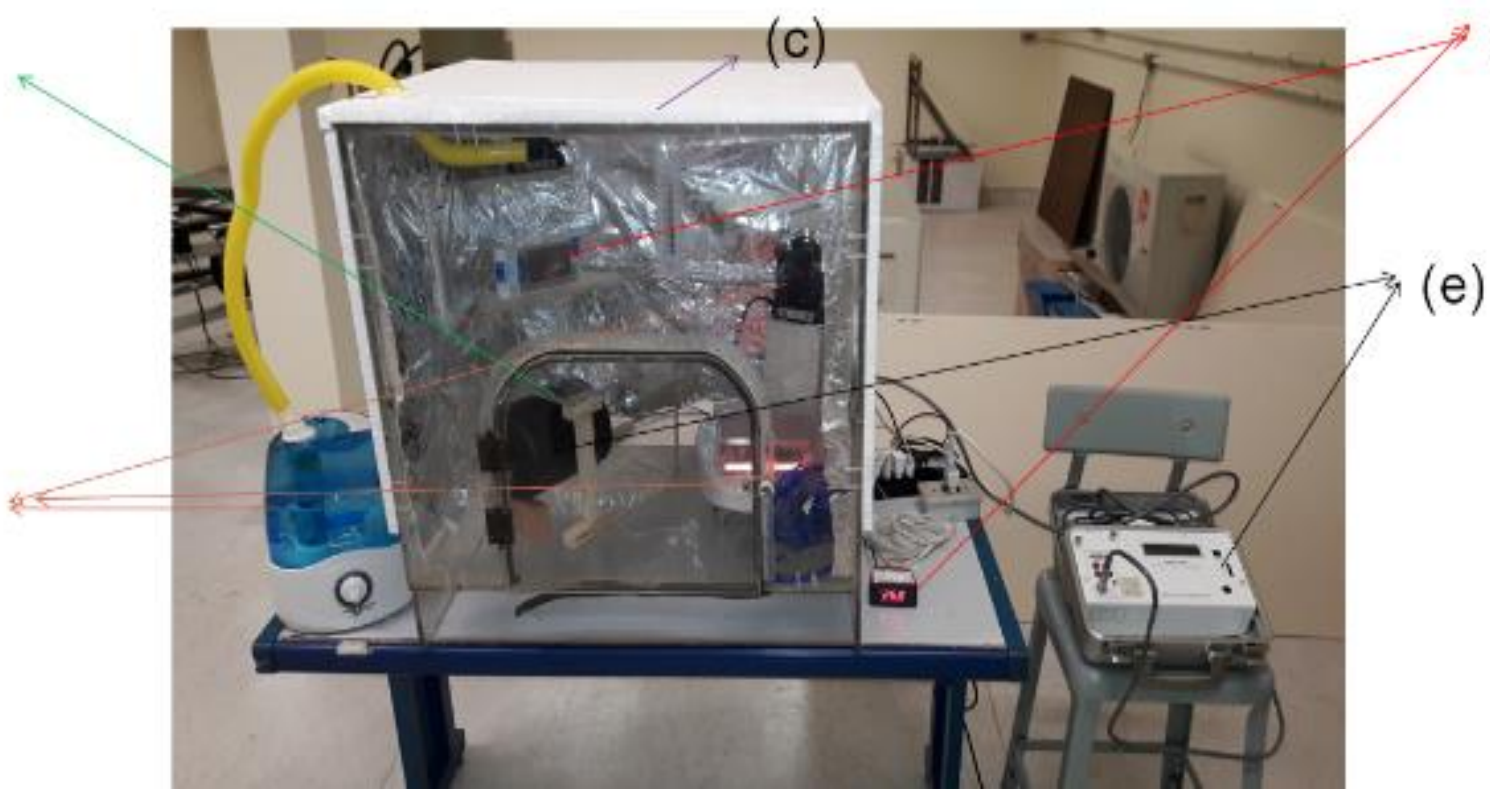

Figure 3: (a) Heating, humidity and ventilation systems, (b) Temperature control systems, (c) Thermal insulation, (d) Irradiation system, (e) Detection system

Source: Author

In Figure 4, we schematically detail the item (d) highlighted in Figure 3, concerning the positioning of the control source that makes up the irradiation system. 


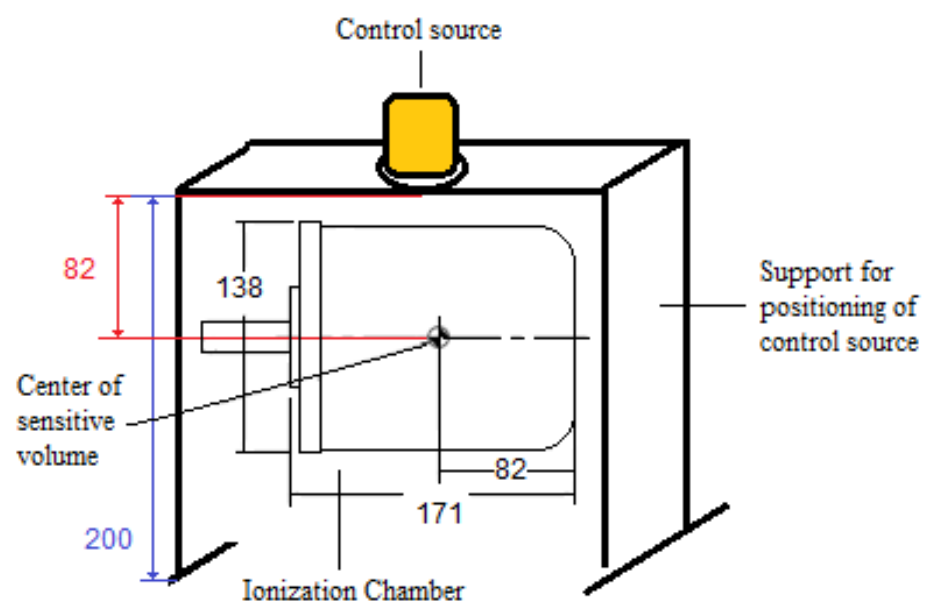

Dimension in millimeters

Figure 4: (d) Irradiation system scheme

\section{RESULTS AND DISCUSSION}

Table 3 shows the results obtained for the measurement system in a climate simulation, using the annual averages of temperature and humidity in the four selected time intervals. The measurements were made with and without the verification source. The measurement without the check source represents a leakage measurement. As the ionization chamber used in this work is not sealed, it was necessary to correct all obtained lectures by the normal temperature and pressure values. It is possible to see that the initial leakage value $(1.41 \mathrm{mGy} / \mathrm{min})$ was increased in all cases up to almost two and a half times by the end of the day. This fact shows that the climatic conditions, even correcting the measurements, can influence the behavior of the ionization chamber in a short time of use. 
Table 3: Brazil - North Region -Amazonas State - Manaus Period of data capture: March 27, 2017until March 28, 2018

\begin{tabular}{|c|c|c|c|c|c|}
\hline & $\begin{array}{c}\text { Temperature } \\
\left({ }^{\circ} \mathrm{C}\right)\end{array}$ & $\begin{array}{c}\text { Humidity } \\
(\%)\end{array}$ & $\begin{array}{c}\text { M1 } \\
(\mu \mathrm{Gy} / \mathrm{min})\end{array}$ & $\begin{array}{c}\text { M2 } \\
(\mu \mathrm{Gy} / \mathrm{min})\end{array}$ & $\begin{array}{l}\mathrm{Cv} \\
(\%)\end{array}$ \\
\hline $\begin{array}{c}\text { Condition } \\
\text { initial }\end{array}$ & 22.4 & 66 & $29.34 \pm 0.45$ & $1.41 \pm 0.04$ & 4.8 \\
\hline $\begin{array}{c}\text { Simulated } \\
\text { Period }\end{array}$ & $\begin{array}{c}\text { Average } \\
\text { temperature } \\
\text { in the period } \\
\left({ }^{\circ} \mathrm{C}\right)\end{array}$ & $\begin{array}{c}\text { Average } \\
\text { humidity in } \\
\text { the period } \\
(\%)\end{array}$ & $\begin{array}{c}\text { M1 } \\
(\mu \mathrm{Gy} / \mathrm{min})\end{array}$ & $\begin{array}{c}\mathrm{M2} \\
(\mu \mathrm{Gy} / \mathrm{min})\end{array}$ & $\begin{array}{l}\mathrm{Cv} \\
(\%)\end{array}$ \\
\hline $7 h-9 h$ & $25.86 \pm 0.04$ & $85.39 \pm 0.20$ & $30.81 \pm 0.46$ & $2.41 \pm 0.04$ & 7.8 \\
\hline $10 h-12 h$ & $26.44 \pm 0.05$ & $85.47 \pm 0.21$ & $30.93 \pm 0.46$ & $2.44 \pm 0.04$ & 7.9 \\
\hline $13 h-15 h$ & $29.76 \pm 0.07$ & $74.02 \pm 0.33$ & $31.91 \pm 0.48$ & $3.38 \pm 0.05$ & 10.6 \\
\hline $16 h-18 h$ & $31.26 \pm 0.08$ & $67.60 \pm 0.40$ & $32.29 \pm 0.48$ & $3.51 \pm 0.06$ & 10.9 \\
\hline
\end{tabular}

M1 - Measurement with checksource

M2 - Measurement without check source

$\mathrm{Cv}$ - Leakage variation coefficient in relation to rates (\%)

From the values obtained during the climate simulation test, it was observed that in each acclimatization of the measurement system for the temperature and humidity parameters there was variation in the IC behavior. For the first simulated period, there was an increase of $3 \%$ in relation to the coefficient of variation of the initial conditions $(\mathrm{Cv})$. In the second period, $3.1 \%$, in the third period, $5.8 \%$ and in the fourth and last simulated period, $6.1 \%$. All simulated points presented a coefficient of variation $(\mathrm{Cv})$ above $5 \%$, tolerance recommended by the current standard. There was an increase in current leakage due to climatic variations.

\section{CONCLUSION}

Preliminary results point to an increase in the accumulated measurements obtained with the ionization chamber due to simulated climatic conditions, being more significant in the measurements made without the verification source (table 3 - M2). 
The humidity parameter directly interfered with the background value measured by the ionization chamber, in the fourth simulated period there was a reduction of the average simulated humidity to $67 \%$, but the ionization chamber continued to present a significant current leakage after the test. This indicates that the dosimetric system must undergo a dehumidification process, before the next use.

Selecting and using appropriate detection equipment for radiometric measurement anywhere in Brazil is a challenge. Although determining the influence of external environmental factors is not an easy task. It is critical to measurement reliability, the establishment of radioprotection systems and the improvement of quality control.

Preliminary data indicate that the system developed and the methodology proposed in this work are feasible and reproducible, allowing the simulation of environmental tests for the humidity and temperature parameters of several ionization chamber models.

\section{ACKNOWLEDGMENT}

The authors acknowledge the partial financial support of the CAPES, FAPESP, CNPq and INCT (project: Radiation Metrology in Medicine) for the partial financial support.

\section{REFERENCES}

[1] ROS, R. A. Metodologia de controle de qualidade de equipamentos de raios X (nível diagnóstico) utilizados em calibração de equipamentos. 2000. 107p. Dissertação (Mestrado em Tecnologia Nuclear) - Instituto de Pesquisas Energéticas e Nucleares, IPEN-CNEN/SP, São Paulo. Disponível em: <http//www.teses.usp.br> Acesso em: 20 outubro 2017

[2] BRASIL. Portaria 453, de 02 de junho de 1998. Diretrizes de proteção radiológica em radiodiagnóstico médico e odontológico Ministério da Saude, Brasília, DF, Disponível em http:// www.conter.gov.br/uploads/legislativo/portaria_453.pdf $>$ Acesso em 15 ago 2017 
[3] AGÊNCIA NACIONAL DE VIGILÂNCIA SANITÁRIA, Radiodiagnóstico Médico: Desempenho de Equipamentos e Segurança,1ed. Brasília 2005

[4] EUROPEAN STANDARD. Medical electrical equipment - Dosimeters with ionization chambers and/or semi-conductor detectors as used in X-ray diagnosis imaging, 2013 (IEC 61674)

[5] INTERNATIONAL STANDARD. Radiological protection $\mathbf{x}$ and gamma reference radiation for calibrating dosemeters and doserate meters and for determining their response as a function of photon energy, 2019 (ISO 4037)

[6] INMET - Instituto Nacional de Meteorologia, Disponivel: <http://www.inmet.gov.br/portal/index.php?r=estacoes/estacoesAutomatica $>$, acesso em 28 março 2018 